\title{
Chlamydia pneumoniae aggravates vein graft intimal hyperplasia in a rat model
}

\author{
Geoffrey TL Kloppenburg*1, Rick de Graaf², Gert ELM Grauls1, \\ Cathrien A Bruggeman ${ }^{1}$ and Frank R Stassen ${ }^{1}$
}

\begin{abstract}
Address: ${ }^{1}$ Cardiovascular Research Institute Maastricht, Department of Medical Microbiology, Academic Hospital Maastricht/Maastricht University, Maastricht, MD Maastricht, The Netherlands and 2Cardiovascular Research Institute Maastricht, Department of Radiology, Academic Hospital Maastricht/Maastricht University, Maastricht, P.O. Box 6166200 MD Maastricht, The Netherlands

Email: Geoffrey TL Kloppenburg* - geoffrey_kloppenburg@hotmail.com; Rick de Graaf - RDGR@radiology.azm.nl; Gert ELM Grauls - ggr@lmib.azm.nl; Cathrien A Bruggeman - cbr@lmib.azm.nl; Frank R Stassen - f.stassen@medmic.unimaas.nl

* Corresponding author
\end{abstract}

Published: 6 December 2007

BMC Microbiology 2007, 7:III doi:10.1 |86/|47|-2180-7-III
Received: 29 January 2007

Accepted: 6 December 2007

This article is available from: http://www.biomedcentral.com/I47I-2180/7/III

(C) 2007 Kloppenburg et al; licensee BioMed Central Ltd.

This is an Open Access article distributed under the terms of the Creative Commons Attribution License (http://creativecommons.org/licenses/by/2.0), which permits unrestricted use, distribution, and reproduction in any medium, provided the original work is properly cited.

\begin{abstract}
Background: Along with angioplasty, autologus vein grafts are commonly used for artery bypass grafting in patients with advanced arterial stenosis and drug-resistant angina pectoris. Although initially a successful procedure, long-term functionality is limited due to proliferation and migration of smooth muscle cells. Like in atherosclerosis, common chronic infections caused by viruses and bacteria may contribute to this process of vein graft failure. Here we investigated the possible role of Chlamydia pneumoniae ( $\mathrm{Cpn}$ ) in the pathogenesis of venous graft failure in an experimental animal model. In 2 groups ( $\mathrm{n}=10$ rats/group), an epigastric vein-to-common femoral artery interposition graft was placed. Immediately thereafter, rats were infected with $C_{p n}\left(5^{*} 10^{8} \mathrm{IFU}\right)$ or injected with control solutions. Rats were sacrificed three weeks after surgery and the grafts were harvested for morphometrical and immunohistochemical analysis.
\end{abstract}

Results: $C_{p n}$ administration immediately after vein grafting resulted in a significant increase in medial cross-sectional area, wall thickness and total wall area. There were no significant differences in T-cell or macrophage influx. Likewise, although positive immunostaining for both HSP60 and CRP could be detected, no differences were found between groups. Based on the observation that the number of cells $/ \mu \mathrm{m}^{2}$ was also not altered, we conclude that $C_{p n}$ infection stimulates smooth muscle cell proliferation by hereunto unknown molecular mechanisms, resulting in a significant increase in intimal hyperplasia.

Conclusion: In conclusion, in a well defined animal model we present here for the first time evidence for a role of Chlamydia pneumoniae in the process of venous graft failure.

\section{Background}

Besides internal mammary arteries, autologus saphenous vein grafts are commonly used for coronary artery bypass grafting (CABG) in angina pectoris patients, resistant to aggressive medical therapy or patients with advanced cor- onary artery stenosis not suitable for percutaneous transluminal coronary angioplasty (PTCA). Although the initial results of venous grafts are excellent, the symptoms tend to recur due to vein graft degeneration and stenosis greatly limiting the long term success of bypass surgery. 
Early failure occurs within the first 1 to 2 months probably from primary thrombosis often due to technical failure or poor runoff in severely stenotic distal coronary arteries [1]. Late failure occurs from several months to years after bypass surgery and is caused by neointimal hyperplasia (NIH) with subsequent atherosclerosis in the saphenous vein graft [2]. NIH, defined as the accumulation of phenotypically altered medial smooth muscle cells (SMC) and extracellular matrix in the intimal component of the vein, is most prominent in the venous graft within the first year. Several factors interact to influence the development of NIH mostly initiated by ischemia of the venous wall, mechanical trauma and hemodynamic stress. Moreover, convincing evidence suggested that NIH is associated with extensive endothelial denudation and destruction of venous grafts [3], resembling a response to injury as seen after angioplasty often leading to restenosis of the denuded artery.

Today it is generally accepted that atherosclerosis is an inflammatory diseases and that atherogenesis as well as disease progression result from inflammation and immune responses towards various stimuli. Common chronic infections caused by viruses and bacteria have been suggested to contribute to this inflammatory process. Most compelling evidence comes from data concerning the intracellular pathogen Chlamydia pneumonia $(C p n)$. Although this bacterium was initially identified as a causative factor in (a-)symptomatic inflammation of the airways, clinical studies demonstrated that patients with high titers of antibody against Cpn have an increased risk for cardiovascular complications $[4,5]$. This is supported by studies revealing significant accelerations of lesion development in animals and a large variety of pro-atherogenic effects in vitro [6-8]. In addition, recent studies have shown that Cpn infection promotes a proliferative phenotype in the vasculature, which makes Cpn also a likely risk factor for vein graft failure $[9,10]$. This is supported by the work of Bartels et al., who observed a strong correlation between elevated Cpn IgG titers and the detection of Cpn in occluded vein grafts [11]. Similar data were shown by Zorc et al., implicating a possible relationship between Cpn presence and occluded arterial bypass grafts [12]. These studies suggest that Cpn is present in occluded grafts, however, experimental evidence for this is currently lacking. In the present paper we addressed this by examining the contribution of Cpn to neointimal hyperplasia in a well defined animal model for autologous vein grafting. To our knowledge this is the first paper which addresses the possible contribution of Cpn infection to the pathogenesis of venous graft failure in an experimental model.

\section{Results}

\section{Animal condition and grafts}

Starting body weight ranged from $250 \mathrm{~g}$ to $350 \mathrm{~g}$, while at the end of the experimental period animal weight ranged from $320 \mathrm{~g}$ to $400 \mathrm{~g}$. No differences in body weight were observed between experimental groups. During the experimental phase no apparent clinical signs of illness were observed in any of the animals. The overall graft patency after three weeks was $90 \%$. Early thrombosis seemed the underlying cause of the failed grafts. No structural anomalies at the anastomotic regions of the grafts were observed.

\section{Chlamydia pneumoniae aggravates intimal hyperplasia through stimulation of SMC proliferation}

Three weeks after bypass grafting in all veins a significant increase in medial thickness was observed (medial thickness in normal, non-grafted vein: $10 \pm 2 \mu \mathrm{m}$ vs. $36 \pm 3 \mu \mathrm{m}$ in grafted vein of the control group) and showed neointimal thickening, which is principally absent in non-grafted control veins.Cpn administration immediately after vein grafting resulted in a significant increase in the medial thickness (Cpn-group: $50 \pm 3 \mu \mathrm{m}$ vs. control group: $36 \pm 3$ $\mu \mathrm{m}, \mathrm{p} \leq 0.05)$, total wall cross-sectional area (Cpn-group: $184200 \pm 57932 \mu \mathrm{m}^{2}$ vs. control group: $75359 \pm 15473$ $\left.\mu \mathrm{m}^{2}, \mathrm{p} \leq 0.05\right)$ and medial cross-sectional area (Cpngroup: $101731 \pm 22984 \mu \mathrm{m}^{2}$ vs. control group: $54149 \pm$ $13960 \mu \mathrm{m}^{2}, \mathrm{p} \leq 0.05$ ) at 3 weeks post surgery (Figure 1).

Next, we tried to determine whether the increase in crosssectional area results from a concomitant increase in cell number or whether the increase is due to cellular hypertrophy, interstitial oedema or an increase in extracellular matrix components. Therefore, we determined cellular density. Our finding that the average number of cells $/ \mu \mathrm{m}^{2}$ was not significantly different between groups (Cpngroup: $5.0 \pm 0.7 \times 10^{-3}$ cells/ $\mu \mathrm{m}^{2}$ vs. control group: $4.1 \pm$ $0.5 \times 10^{-3}$ cells $/ \mu \mathrm{m}^{2}$ ), suggests that Cpn infection stimulates cell proliferation but not cellular hypertrophy or interstitial oedema or an increase in extracellular matrix components. After all, the latter are expected to reduce cellular density, a phenomenon which was not observed.

\section{Influx of inflammatory cells}

Staining for inflammatory cells in the venous graft showed a minimal influx of T-cells at three weeks after surgery with an average of one to three T-cells per crosssection. No significant differences between experimental groups were observed. On the other hand, macrophages were notably present in the subendothelial area and in the media, however with a with a wide variance. Therefore, no significant differences between groups were found. Moreover, alpha-actin staining showed SMC to be the main content of the intima and media with little extra-cellular matrix accumulation in both groups, confirming that the 

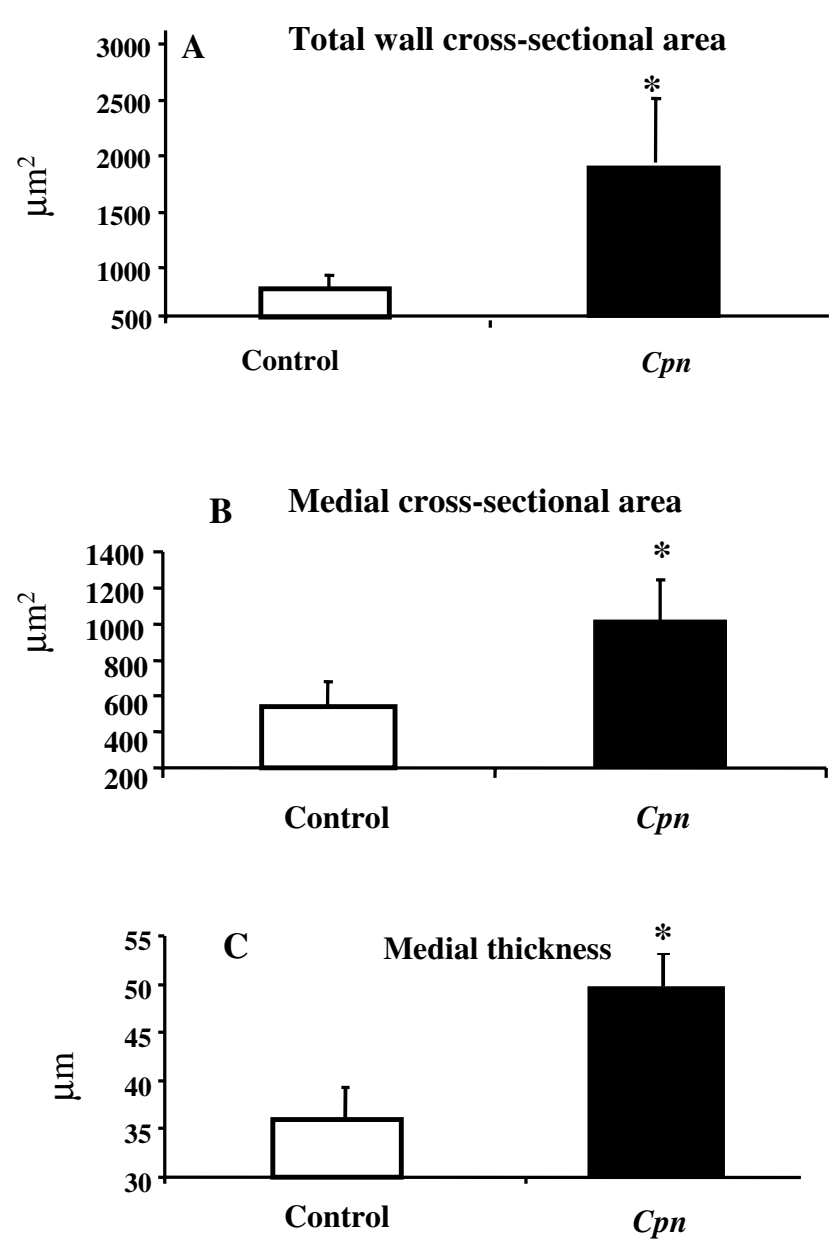

Figure I

Effect of Cpn administration on total wall (A) cross-sectional area, medial cross-sectional area (B) and wall thickness (C) three weeks after vein grafting. $* \mathrm{P}<0.05$ (values compared with control).

increase in wall mass is predominantly due to smooth muscle cell proliferation.

\section{C-reactive protein}

We also performed an immunostaining to reveal the presence of C-reactive protein (CRP) in the venous graft. Although predominantly produced by the liver, local production of CRP by SMC in response to inflammatory cytokines has also been demonstrated recently [13]. Also, evidence suggests that CRP is involved in smooth muscle cell migration and proliferation [14]. Truly, positive staining for CRP could be detected mainly in the subendothelial area (typical example shown in Figure 2A). Nonetheless, when stainings were quantified in a semiquantitative manner, no significant differences were observed between groups (Cpn-infected: $2.5 \pm 0.8$ v.s. control group $2.4 \pm 0.5$, n.s.) .

\section{Heat shock protein 60}

Previously we demonstrated the noticeable presence of heat shock protein 60 (HSP60) in occluded veins [15]. Furthermore, we were able to demonstrate that HSP60 is able to stimulate SMC proliferation in a TLR2/4 dependent way [15]. To determine whether HSP60 also plays a role in graft failure in the present model and whether $C p n$ affects the presence of HSP60 in the grafts, we stained HSP60 in grafts from both the control group and the Cpninfected group. Indeed, HSP60 positive staining could be revealed in both groups (typical example shown in Figure 2C). Also, semi-quantitative analysis showed a trend towards a more intense HSP60 signal in the Cpn-infected group (Cpn-group: $3.3 \pm 0.5$ v.s. control group: $2.8 \pm 0.7$, n.s.), although the difference was not statistically significant.

\section{Discussion}

Saphenous vein graft failure is a common problem after CABG. Approximately $15 \%$ to $30 \%$ of vein grafts occlude during the first year increasing up to $50 \%$ within 10 years [16]. Graft failure occurring within one month after surgery is almost always caused by thrombosis. Neointimal hyperplasia as defined as the accumulation of SMC and extracellular matrix in the intimal layer follows a similar pattern in the balloon injured artery or vein graft and is the major disease process in the vein graft resulting in failure during the first year [17]. Nearly all veins implanted into the arterial circulation develop intimal wall thickening thereby reducing the lumen size. This is confirmed by our results in the rat venous graft model. At 3 weeks post transplantation, a significant increase in both total and medial cross-sectional area as well as media thickness was observed in the epigastric vein grafts, which is in agreement with earlier data from Hoch and colleagues [18].

To unravel the underlying molecular mechanisms contributing to the pathology of vein graft failure a large variety of studies have been carried out of the past decades in order to find an effective intervention. However, until now these mechanisms haven't been completely elucidated yet. Recently, sero-epidemiologic studies have suggested a role for Cpn the development of vascular disease. Cpn is an obligatory intracellular Gram-negative bacterium that was first isolated as a respiratory pathogen. This micro-organism has also been isolated from coronary arteries of patients with acute coronary syndrome [12], as well as from carotid arteries [19], the aorta and peripheral arteries [20]. These observations in combination with multiple in vitro findings [7] demonstrating a stimulating effect of Cpn on SMC proliferation, supported a role for Cpn in obstructive vascular disease. Nonetheless, in contrast to atherosclerosis, a possible role of Cpn in venous bypass failure has been less subject of study. Bartels et al.[21] studied the prevalence of Cpn in occluded vein 

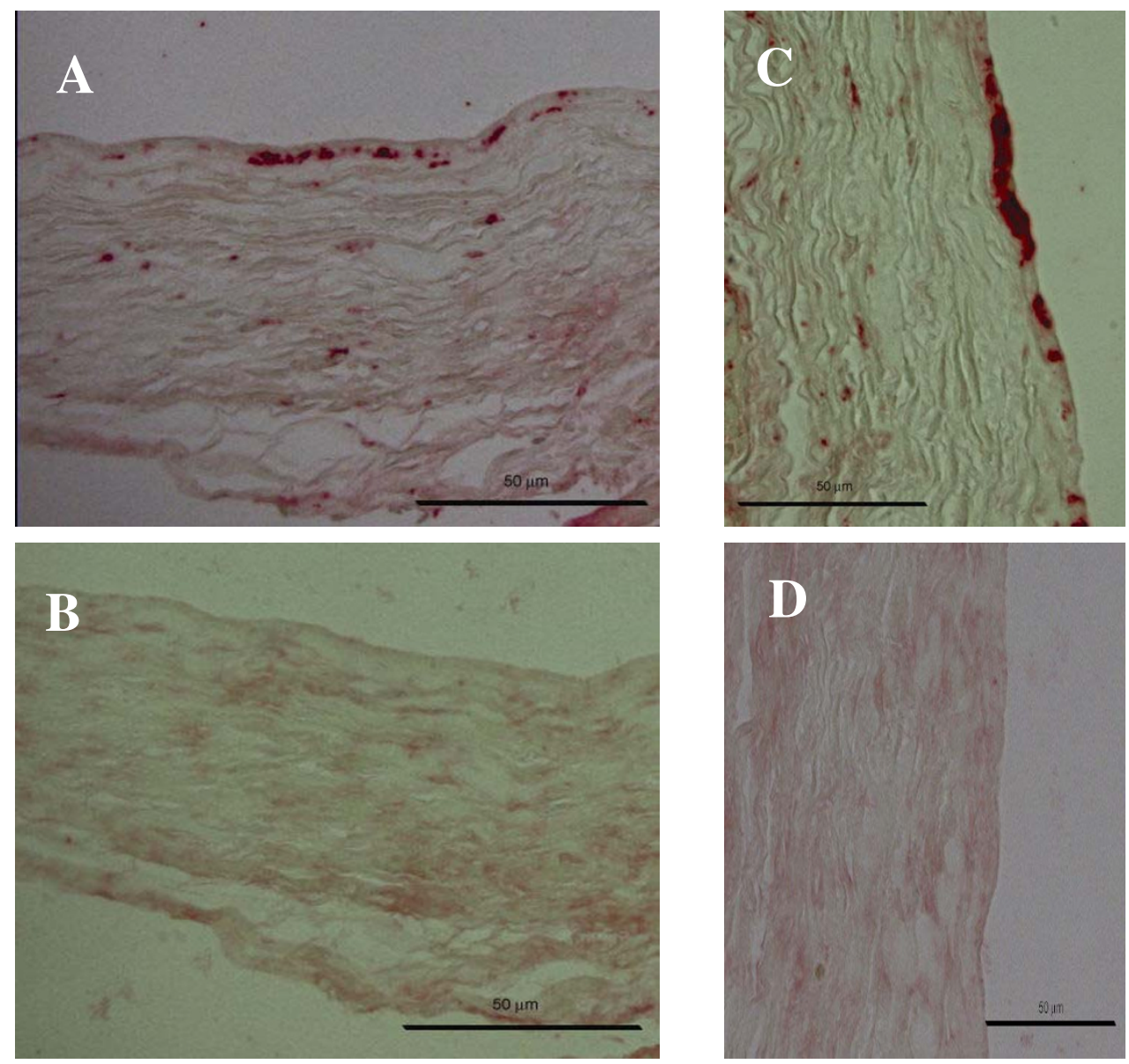

\section{Figure 2}

Photomicrographs showing subsequent immunolabeling of a venous bypass graft 3 weeks after surgery (A: CRP, C:HSP60) as well as their representative negative controls $(B, D)$.

grafts and native saphenous veins and showed that Cpn was frequently present in occluded CABG but not in normal veins. Cpn DNA could be detected by PCR in $25 \%$ of the cases, while viable Cpn was recovered from $16 \%$ of occluded vein grafts. In this study we present for the first time evidence for a role for $C p n$ in venous graft failure.

When rats were infected with Cpn immediately after surgery, a significant increase in media thickness and total wall cross-sectional area was observed in the epigastric vein-to-common femoral artery graft. To unravel a potential mechanism which might explain the effect of Cpn on intima hyperplasia, we first evaluated the presence of inflammatory cells in the graft. Focal endothelial disruption, occurring during all vein graft harvesting, leads to adherence of platelets and monocytes. Several lines of evidence suggest that $C p n$ replicate within alveolar cells and can make its way into the wall of the healing graft by using macrophages and monocytes as vectors [22]. Once present in the vascular wall, Cpn may further enhance the influx of monocytes through the release of monocyte chemoattractant protein 1 by VSMC's. Chronic macrophage infection contributes to local inflammation but it remains unclear whether this aggravates intimal hyperplasia and bypass failure. Hoch et al. demonstrated that depletion of macrophages suppresses intimal hyperplasia indicating the importance of the amount of macrophages present in the graft [18]. However immunostaining of the venous graft in our model showed no differences in influx of inflammatory cells between the Cpn infected and the control group, suggesting a different mechanism of action.

Cpn infection of vascular smooth muscle cells increases interleukin-6 (IL-6) secretion in vitro [23]. In vivo, IL-6 is a strong inducer of liver C-reactive protein (CRP) production which is able to stimulate endothelial and smooth muscle cell proliferation providing a pathway for Cpn to aggravate vein graft failure [24]. In addition, evidence is 
accumulating suggesting that SMC are able to produce CRP and stimulate SMC migration and proliferation in an autocrine fashion [14]. Indeed, we were able to demonstrate the presence of CRP in particular in the subendothelial layer thereby providing further evidence for a role for CRP in intima hyperplasia. Nonetheless, no difference between the two groups were observed indicating that Cpn infection does not have an effect on the presence of CRP in the vascular wall at the time point examined. Nevertheless, this does not exclude that Cpn may affect the production of CRP at earlier time points post surgery and contribute as such to the process already at an earlier stage. Further studies are required to unravel this aspect in more detail.

Cpn is also known to produces large amounts of heat shock protein 60 (HSP 60) during chronic, persistent infections [25]. Cpn HSP60, which is well conserved during evolution and shows a high degree of homology with mammalian HSP60, is able to activate vascular endothelium, smooth muscle cells, and macrophages [26]. HSP60 is also able to stimulate SMC proliferation [15,27] and may hereby aggravate a hyperplastic response as seen in our model. Therefore, we decided to determine the presence of HSP60 by immunohistochemistry. Actually we were well able to visualize the presence of HSP60 in the grafts of both groups; however, despite the fact that there was a trend towards an increase in the presence of HSP 60 in the venous grafts of the Cpn-infected group as compared to the controls, this failed to reach statistical significance.

\section{Conclusion}

Summarizing, we present here for the first time evidence for a possible role of Chlamydia pneumoniae in the process of venous graft failure. In a well defined animal model, a significant increase in both total and media cross-sectional area as well as media thickness was observed in vein grafts obtained from Cpn-infected rats, suggesting that Cpn is able to promote the process of intima hyperplasia. Furthermore, cellular density in the vascular wall remained constant indicating that Cpn stimulates cell proliferation but not hypertrophy nor the formation of institial oedema or the deposition of extracellular matrix components. In addition, we analyzed in more details some of the possible molecular mechanisms which may contribute to the observed Cpn-mediated effects. However, none of the suggested mechanisms (enhanced influx of inflammatory cells, augmented production of CRP or HSP60) seemed primarily responsible for the observed effects and further research is warranted to elucidate in more detail how Cpn affects vein graft failure.

\section{Methods \\ Animals and Vein Grafting Procedure}

Male inbred specific pathogen free (SPF) male Lewis (LEW) rats were obtained form the Department of Experimental Animal service of the University of Maastricht, the Netherlands. Experiments were carried out on animals aged 12 weeks weighing 250-350 gram. Housing and care of the animals, and all the procedures used in this study were approved by the Ethical Committee for the Use of Experimental Animals of the institution, and conform the Guide for the Care and the Use of Laboratory Animals, published by the US National Institute of Health (NIH Publication No. 85-23, revised 1985). Rats were fed standard rat chow and tap water at libitum. All surgical procedures were performed under general anesthesia and using sterile techniques. Epigastric vein-to-common femoral artery interposition grafts were placed in rats in a similar way as previously described by Hoch et al.[28]. In brief, each animal was anesthetized with an intraperitoneal (i.p.) injection of pentobarbital sodium $(60 \mathrm{mg} / \mathrm{kg})$. An 8 $\mathrm{mm}$ segment of ipsilateral epigastric vein was carefully harvested, gently irrigated with heparinized saline solution $(100 \mathrm{U} / \mathrm{ml})$, and placed as reverse interposition graft into a segmental $3 \mathrm{~mm}$ defect of the common femoral artery with 8 to 10 interrupted sutures of $11-0$ nylon (Ethicon). The entire procedure was carried out with standard microsurgical techniques. The total ischemic time was kept to less than $30 \mathrm{~min}$. Graft patency, defined as a condition of flow through the graft, was verified by visual inspection at the end of the surgical procedure.

\section{Experimental Design}

Two experimental groups were used. Directly after the grafting procedure, rats $(\mathrm{n}=10$ animals/group) were either Cpn-infected by i.p. injection ( $1 \mathrm{ml}$ of $5 \times 10^{8}$ inclusion forming units (IFU) dissolved in a sucrose-phosphate-glucose solution) or received a $1 \mathrm{ml}$ i.p. injection of a sucrose-phosphate-glucose solution. The i.p. inoculation route instead of the intranasal route was used because of the high infectious dosage required in rat experiments. Previous experiments done in our laboratory have demonstrated no significant differences in systemic dissemination of Cpn between intranasal and i.p. injection (Ezzahiri, personal communication).

\section{Histological and morphometrical procedures}

Three weeks after surgery, rats were anaesthetized, the chest and abdominal cavities were opened and a catheter was inserted into the apex of the heart. Vessels were initially flushed with physiological salt solution and then perfusion fixed with 3,7\% formaldehyde in phosphatebuffered saline (PBS, pH 7.4) at physiological pressure $(100 \mathrm{mmHg})$. Vein grafts were removed and fixed overnight in the same fixative and routinely processed for paraffin embedding. Cross-sections $\left(\begin{array}{lll}4 & \mu \mathrm{m})\end{array}\right.$ were 
haematoxylin-eosin or Lawson stained for morphometrical analysis (average of three cross-sections per graft). Intimal and medial areas were quantified using a computerassisted morphometry system (analySIS ${ }^{\varpi}$, Soft Imaging System, GmbH). The cross-sectional area of the media was defined as the area surrounded by the external and internal elastic lamina. The neointimal cross-sectional area was defined by the area surrounded by the internal elastic lamina and the arterial lumen. Final scores were given as means \pm SEM.

\section{Quantification of cell number in the intima and media}

The number of cells in the intima and media was quantified by counting the total number of nuclei using a microscope. All nuclei were counted in haematoxylin-eosin stained cross-sections. Final scores were expressed as number of cells per area and values are given as means \pm S.E.M

\section{Immunohistochemistry}

Paraffin sections $(4 \mu \mathrm{m})$, taken from vein grafts three weeks after surgery, were routinely processed and stained with the two-layer indirect immunoperoxidase technique using monoclonal antibodies (mAb).

The following mAbs were used in this study: Anti-rat CD3 (Sera-lab, Crawley Down, UK), a mouse mAb against Tcells; anti- $\alpha$ smooth muscle actin (ASMA, Sigma, Missouri, USA), ED-1, a mouse mAb to monocytes/macrophages (kindly supplied by Dr. A.M. Duijvestijn Dept. of Immunology, University Maastricht, the Netherlands), a rabbit anti-HSP60 (CST, Danvers, USA) and anti-CRP (R\&D systems, Minneapolis, USA) a mouse mAb against C-reactive protein.

Sections were incubated with $2 \%$ BSA/PBS (ED-1, CRP and ASMA) for 15 min at room temperature and treated with antigen retrieval buffer (CD3) for $25 \mathrm{~min}$ at $95^{\circ} \mathrm{C}$ [13]. Sections for HSP60 staining were incubated with 10 mM sodium citrate buffer $\mathrm{pH} 6.0$ and microwave boiled for $10 \mathrm{~min}$ at $95-99^{\circ} \mathrm{C}$. Monoclonals were diluted (ED-1 1/20, ASMA 1/1500, CD3 1/400, CRP 1/100) in PBS and applied to the slides for $60 \mathrm{~min}$ at $37^{\circ} \mathrm{C}$. HSP60 monoclonals were diluted $1 / 100$ in PBS and applied to the slides overnight at $4^{\circ} \mathrm{C}$. After three wash steps with PBS for $5 \mathrm{~min}$, a biotinylated goat anti-mouse secondary antibody (1/1200, DAKO Glostrup Denmark) was applied for $30 \mathrm{~min}$ at room temperature. Finally, sections were incubated with alkaline phosphatase-coupled streptavidin (ABC reagent, Vector Laboratories), followed by immunodetection using fast red as a substrate. To visualize nuclei, sections were counterstained with haematoxylin. Then, the presence of positive cells was analyzed by microscopy and scored semi-quantitatively, using a zero to four scale with zero meaning no positive signal and 4 extremely positive, by an observer blinded to the experimental groups. Final values were expressed as mean \pm S.E.M

\section{Statistical analysis}

Morphometrical data and cell count numbers are expressed as means \pm S.E.M. Values were compared using the Mann Whitney $U$ test and $\mathrm{p}<0.05$ was considered as statistically significant.

\section{Authors' contributions}

GK: surgical procedures, morphometric analyses, drafting the manuscript

RdG: immunohistochemistry

GG: semi-quantitative analyses of immunohistochemical stainings, culturing of Chlamydia pneumoniae

CB: participated in the study design and coordination

FS: participated in the study design, coordination and in drafting the manuscript

All authors read and approved the final manuscript.

\section{Acknowledgements}

Both GK and RdG are supported by a grant from the Kootstra talent fellowship.

\section{References}

I. Cox J, Chiasson DA, Gotlieb Al: Stranger in a strange land: the pathogenesis of saphenous vein graft stenosis with emphasis on structural and functional differences between veins and arteries. Prog Cardiovasc Dis 1991, 34:45-68.

2. Nwasokwa ON: Coronary artery bypass graft disease. Ann Intern Med 1995, I 23:528-45.

3. LoGerfo FW, Quist WC, Cantelmo NL, Haudenschild CC: Integrity of vein grafts as a function of initial intimal and medial preservation. Circulation 1983, 68:III I7-24.

4. Wimmer ML, Sandmann-Strupp R, Saikku P, Haberl RL: Association of chlamydial infection with cerebrovascular disease. Stroke 1996, 27:2207-10.

5. Saikku P, Mattila K, Nieminen MS, Huttunen JK, Leinonen M, Ekman $M-R$, Mäkelä PH, Valtonen V: Serological evidence of an association of a novel Chlamydia, TWAR, with chronic coronary heart disease and acute myocardial infarction. Lancet 1988 , 332:983-6.

6. Ezzahiri R, Nelissen-Vrancken HJ, Kurvers HA, Stassen FR, Vliegen I, Grauls GE, van Pul MM, Kitslaar PJ, Bruggeman CA: Chlamydophila pneumoniae (Chlamydia pneumoniae) accelerates the formation of complex atherosclerotic lesions in Apo E3-Leiden mice. Cardiovasc Res 2002, 56:269-76.

7. Mahony JB, Coombes BK: Chlamydia pneumoniae and atherosclerosis: does the evidence support a causal or contributory role? FEMS Microbiol Lett 2001, I97:1-9.

8. Campbell LA, Kuo CC: Chlamydia pneumoniae - an infectious risk factor for atherosclerosis? Nat Rev Microbiol 2004, 2:23-32.

9. Rupp J, Hellwig-Burgel T, Wobbe V, Seitzer U, Brandt E, Maass M: Chlamydia pneumoniae infection promotes a proliferative phenotype in the vasculature through Egr-I activation in vitro and in vivo. Proc Natl Acad Sci USA 2005, I 02:3447-3452.

10. Hirono S, Dibrov E, Hurtado C, Kostenuk A, Ducas R, Pierce GN: Chlamydia pneumoniae stimulates proliferation of vascular 
smooth muscle cells through induction of endogenous heat shock protein 60. Circ Res 2003, 93:710-716.

II. Bartels C, Maas M, Bein G, Brill N, Bechtel JF, Leyh R, Sievers HH: Association of serology with the endovascular presence of Chlamydia pneumoniae and cytomegalovirus in coronary artery and vein graft disease. Circulation 2000, I0I:|37-|4|.

12. Zorc M, Vraspir-Porenta O, Kese D, Petrovic D, Legan M: Detection of Chlamydia pneumoniae DNA in the coronary arteries and bypass in three patients with diffuse coronary artery disease. Cardiology 2005, 103:121-122.

13. Calabro P, Willerson JT, Yeh ET: Inflammatory cytokines stimulated C-reactive protein production by human coronary artery smooth muscle cells. Circulation 2003, 108:1930-1932.

14. Jialal I, Devaraj S, Venugopal SK: C-reactive protein: risk marker or mediator in atherothrombosis? Hypertension 2004, 44:6-I I.

15. de Graaf R, Kloppenburg G, Kitslaar PJ, Bruggeman CA, Stassen F: Human heat shock protein 60 stimulates vascular smooth muscle cell proliferation through Toll-like receptors 2 and 4 . Microbes Infect 2006, 8:1859-1865.

16. Fitzgibbon GM, Kafka HP, Leach AJ, Keon WJ, Hooper GD, Burton JR: Coronary bypass graft fate and patient outcome: angiographic follow-up of 5,065 grafts related to survival and reoperation in I, $\mathbf{3 8 8}$ patients during $\mathbf{2 5}$ years. J Am Coll Cardiol I 996, 28:616-626.

17. Motwani G], Topol Ej: Aortocoronary saphenous vein graft disease: pathogenesis, predisposition, and prevention. Circulation 1998, 97:916-931.

18. Hoch JR, Stark VK, van Rooijen N, Kim JL, Nutt MP, Warner TF: Macrophage depletion alters vein graft intimal hyperplasia. Surgery 1999, 126:428-37.

19. Johnston SC, Zhang H, Messina LM, Lawton MT, Dean D: Chlamydia pneumoniae burden in carotid arteries is associated with upregulation of plaque interleukin- 6 and elevated C-reactive protein in serum. Arterioscler Thromb Vasc Biol 2005, 25:2648-2653.

20. Gutierrez J, Linares-Palomino J, Lopez-Espada C, Rodriguez M, Ros E, Piedrola G, del Maroto MC: Chlamydia pneumoniae DNA in the arterial wall of patients with peripheral vascular disease. Infection 200I, 29: I96-200.

21. Bartels C, Maas M, Bein G, Malisius R, Brill N, Bechtel JF, Sayk F, Feller AC, Sievers HH: Detection of Chlamydia pneumoniae but not cytomegalovirus in occluded saphenous vein coronary artery bypass grafts. Circulation 1999, 99:879-882.

22. Kaukoranta-Tolvanen SS, Teppo AM, Laitinen K, Saikku P, Linnavuori K, Leinonen M: Growth of Chlamydia pneumoniae in cultured human peripheral blood mononuclear cells and induction of a cytokine response. Microb Pathog 1996, 21:215-221.

23. Yang X, Coriolan D, Schultz K, Golenbock DT, Beasley D: Toll-like receptor 2 mediates persistent chemokine release by Chlamydia pneumoniae-infected vascular smooth muscle cells. Arterioscler Thromb Vasc Biol 2005, 25:2308-23।4.

24. Cirillo P, Golino P, Calabro P, Cali G, Ragni M, De Rosa S, Cimmino G, Pacileo M, De Palma R, Forte L, Gargiulo A, Corigliano FG, Angri $V$, Spagnuolo R, Nitsch L, Chiariello M: C-reactive protein induces tissue factor expression and promotes smooth muscle and endothelial cell proliferation. Cardiovasc Res 2005, 68:47-55.

25. Costa CP, Kirschning C], Busch D, Durr S, Jennen L, Heinzmann U, Prebeck S, Wagner H, Miethke T: Role of chlamydial heat shock protein 60 in the stimulation of innate immune cells by Chlamydia pneumoniae. Eur J Immunol 2000, 32:2460-70.

26. Kol A, Bourcier T, Lichtman AH, Libby P: Chlamydial and human heat shock protein $60 \mathrm{~s}$ activate human vascular endothelium, smooth muscle cells, and macrophages. J Clin Invest 1999, 103:57|-7.

27. Sasu S, LaVerda D, Qureshi N, Golenbock DT, Beasley D: Chlamydia pneumoniae and chlamydial heat shock protein 60 stimulate proliferation of human vascular smooth muscle cells via toll-like receptor 4 and p44/p42 mitogen-activated protein kinase activation. Circ Res 200I, 89:244-50.

28. Hoch JR, Stark VK, Hullett DA, Turnipseed WD: Vein graft intimal hyperplasia: leukocytes and cytokine gene expression. Surgery I 16:463-470.
Publish with Biomed Central and every scientist can read your work free of charge

"BioMed Central will be the most significant development for disseminating the results of biomedical research in our lifetime. "

Sir Paul Nurse, Cancer Research UK

Your research papers will be:

- available free of charge to the entire biomedical community

- peer reviewed and published immediately upon acceptance

- cited in PubMed and archived on PubMed Central

- yours - you keep the copyright

Submit your manuscript here:

http://www.biomedcentral.com/info/publishing_adv.asp
BioMedcentral 